\title{
THE CONCENTRATION OF CARBON MONOXIDE IN THE BREATHING AREAS OF WORKERS DURING LOGGING OPERATIONS AT THE MOTOR-MANUAL LEVEL
}

\author{
KRZYSZTOF LESZCZYŃSKI
}

\author{
University of Agriculture in Krakow, Kraków, Poland \\ Department of Forest and Wood Utilization
}

\begin{abstract}
Objectives: This article compares 2 variants of logging technologies at the motor-manual level: variant A - cutting and delimbing by means of a petrol chainsaw, skidding with the use of a cable winch mounted on a tractor $(67-74 \mathrm{~kW})$; variant B - cutting by means of a petrol chainsaw, skidding, debranching and cutting to length by means of a processor aggregated with a farm tractor $(61 \mathrm{~kW})$. Material and Methods: Direct dosimetry and non-parametric (moving block bootstrap) methods were used in order to specify the characteristics of the collected sets. Results: Bootstrap average values show that the average CO concentration at a skidding tractor operator's station during early thinning was $2.54 \mathrm{mg} \times \mathrm{m}^{-3}$. At processor operator's station it amounted to $10.35 \mathrm{mg} \times \mathrm{m}^{-3}$. Such results allow to conclude that a higher CO concentration at the above-mentioned 2 work stations was observed during early thinning. In the case of a petrol chainsaw operator, it was observed that the permissible exposure limit $\left(23 \mathrm{mg} \times \mathrm{m}^{-3}\right)$ was exceeded and the short-term permissible exposure limit $\left(117 \mathrm{mg} \times \mathrm{m}^{-3}\right)$ was not. The average concentration value for a chainsaw operator working individually during late thinning interventions was substantially lower $\left(15.01{\mathrm{mg} \times \mathrm{m}^{-3}}^{-3}\right.$, which results from the lack of technological pressure that can be observed while cooperating with a processor operator. Conclusions: The risk increases along with conditions that generate the concentration of exhaust produced by 2-stroke petrol chainsaw engines.
\end{abstract}

Key words:

Work, Risk, Health, Logging, Forestry

\section{INTRODUCTION}

Air quality is one of the elements in work environment which points to a possible risk of illnesses due to long-term occupational exposure. In industrial conditions, the exhaust concentration is successfully eliminated by means of ventilation devices, chemical changes or other technological solutions. Carbon monoxide (CO) is a colorless, inodorous and toxic gas used in numerous branches of industry or produced in the form of a waste product. Carbon monoxide poisoning symptoms depend on its concentration in the air, the period of its activity and a person's work intensity. Carbon monoxide's close relation to hemoglobin makes it substitute oxygen and form carboxyhemoglobin. CO is also slowly expelled from a human body. Short-term exposures to concentrations of over $2500 \mathrm{mg} \times \mathrm{m}^{-3}$ result in fainting and - in case of no fresh air (oxygen) access - death within

This work was supported by the University of Agriculture in Krakow, Faculty of Forestry under grant DS-3412/KULiD.

Received: January 28, 2014. Accepted: May 7, 2014.

Corresponding author: K. Leszczyński, University of Agriculture in Krakow, Department of Forest and Wood Utilization, 29 Listopada 46, 31-425 Kraków, Poland (e-mail: rlleszcz@cyf-kr.edu.pl). 
just a few minutes, due to brain hypoxia, or the so-called internal suffocation [1].

Poisoning typically takes place in confined spaces with faulty heating installations. It is estimated that $33.5 \%$ of fatal cases in a working environment were caused by carbon monoxide. In forestry, the source of carbon monoxide are petrol-powered engines of tools and machines, heating devices at seed husking plants and retort furnaces used for wood coal (charcoal) production. Carbon monoxide can also be produced during biological processes taking place in seed storages.

In the USA, where prescribed fires are used for carrying out various breeding and protection tasks, the risks caused by air pollution are really considerable. Research shows that the interquartile range of the carbon monoxide concentration in the firemen's breathing area [2] varies from 2.10 to $10.48 \mathrm{ppm}\left(1 \mathrm{ppm} \mathrm{CO}=1.146 \mathrm{mg} \times \mathrm{m}^{-3}\right)$. Another research, on the other hand, proves that the average value of the $\mathrm{CO}$ concentration varies in the range $6-30 \mathrm{ppm} / \mathrm{h}[3]$, depending on the type of tasks performed by fire-fighters.

The exhaust emission in a machine's life cycle is frequently the subject of studies on the influence of timber harvesting on the environment [4]. A forest machines' exhaust emission study [5] points to a 10 times higher carbon monoxide emission in the case of 2-stroke chainsaw engines than in the case of harvesters or forwarders. On the other hand, exhaust emissions from high pressure engines additionally contain certain carcinogenic substances. However, their exposure levels in the open air forest environment is very low and do not exceed occupational exposure limits [6].

During tending interventions, exhaust from tool engines and machine engines is emitted into a space where gas exchange is limited by specific vertical and horizontal structure of a stand. In spite of this fact, the $\mathrm{CO}$ concentration is low enough not to produce death, but high enough to exceed permissible hygienic norms [2,7]. The aim of this study was to specify the amount of the carbon monoxide concentration as well as 15-min short-term carbon monoxide concentration. It included the analysis of the $\mathrm{CO}$ concentration at the working stations of forest machines operators and it was carried out in 2 variants:

- individual work (A) - cutting and debranching by means of a petrol chainsaw, skidding - with the use of a farm tractor equipped with a cable winch;

- pair work (B) - cutting by means of a petrol chainsaw, skidding trees to the route, debranching and cutting to length with the use of a processor aggregated with a farm tractor.

The tests were conducted in coniferous stands during early and late thinning operations.

\section{MATERIAL AND METHODS}

This article compares 2 variants of logging technologies at the motor-manual level:

- variant A - cutting and delimbing by means of a petrol chainsaw, skidding with the use of a Fransgard 6000 cable winch mounted on a Pronar $82(67 \mathrm{~kW})$ or Zetor 6741 (74 kW) tractor;

- variant B - cutting by means of a petrol chainsaw, skidding, debranching and cutting to length by means of a Hypro 450 processor aggregated with an MTZ 820 Belarus $(61 \mathrm{~kW})$ farm tractor.

The experiment was performed in the area of the Regional Directorate of the State Forests in Katowice and Kraków, in the following stands: pine stands (Dąbrowa Tarnowska and Rybnik forest districts), fir stands (Gorlice and Myślenice forest districts) and spruce stands (Nowy Targ and Wisła forest districts). Thinning operations were carried out during the full vegetation process at temperatures varying $12-24^{\circ} \mathrm{C}$. During preparatory work, 3 half-hectare plots were set up for both compared technology variants in 2 categories of interventions (early thinning - ET, late thinning - LT) and 3 types of stands. Thirty-six sample plots were set up in total, on which $380 \mathrm{~m}^{3}$ of timber was logged, including $167 \mathrm{~m}^{3}$ during early thinning of trees 
with an average breast height diameter of $16 \mathrm{~cm}$ in variant $A$ and of $20 \mathrm{~cm}$ in variant $B$ (Table 1).

The research plan entailed measurements of the carbon monoxide concentration level in the breathing area of 4 working stations:

- skidding tractor operator (TO),

- chainsaw operator using skidding tractor technology (CSOVarA),

- chainsaw operator using processor technology (CSO$\operatorname{VarB})$,

- processor operator (PO).

The breathing area was a space restricted to a radius of $30 \mathrm{~cm}$ off the operators' mouths.

In order to specify the concentration of an analyzed factor, a dosimetric measurement method was used, which is a typical method in the case of non-stationary work spaces or spaces with high changeability of physicochemical factors. It was also assumed that the value characterizing the exposure to $\mathrm{CO}$ shall be the expected value weighted by sampling time and constituting a discreet form of a continuous function:

$$
\mathrm{E}(\mathrm{X})=\int_{-} 0^{\wedge} \mathrm{t}[(\mathrm{x} \times \mathrm{dF}(\mathrm{x}))]
$$

where:

$\mathrm{t}$ - stands for the measurement time,

$\mathrm{x}$ - stands for the value of the carbon monoxide concentration.

Time-weighted average (TWA) concentration and 15-min short-term concentration exposure were specified and the uncertainty of measurement was determined for each work station.
Measurements were carried out by means of PAC III E individual dosimeter produced by a German company named Dräger using 1-s sampling rate. A record of 12000 to 23000 values per one measurement session was obtained. In order to balance the experiment, a 3-stage process of systematic sampling without repetition was used [8]. Sampling of 1000 elements was carried out at the level of 1) a single experiment, 2) 3 repetitions in total and 3 ) 3 types of stands (pine, spruce, fir). Consequently, sets characterizing $\mathrm{CO}$ exposure in coniferous stands were obtained for 2 analyzed technology variants (A and B) and 2 interventions (ET and LT).

The initial analysis of the sampled material indicated right-skewness; the smaller the measurements were, the more positive skewness was. The calculated $\mathrm{Chi}^{2}$ statistics (Pearson's Chi test, Table 2) are significantly remote from the boundary value $\mathrm{Chi}^{2}(0.95,16)=26.296$. Therefore, null hypothesis assuming that empirical distribution fits with normal distribution should be rejected at a significance level $\alpha=0.05$. In such case, the interval estimation of unknown probability distribution for dependent data may be highly erroneous [8]. In order to avoid this problem, a resampling method was used for dependent data, as it does not require knowledge on distributions.

The applied statistical technique consists in sampling the original data in order to create new sets of observations, which serve to approximate unknown statistical distributions and estimators [9]. The framework for this type of simulation was specified by Efron in a ground-breaking

Table 1. Logging unit characteristics

\begin{tabular}{lcccc}
\hline \multirow{2}{*}{ Description } & \multicolumn{2}{c}{ Early thinning } & \multicolumn{2}{c}{ Late thinning } \\
\cline { 2 - 4 } & variant A & variant B & variant A & variant B \\
\hline Diameter at 1.3 $\mathrm{m}(\mathrm{cm})$ & 16 & 20 & 28 & 32 \\
Height $(\mathrm{m})$ & 15 & 19 & 23 & 22 \\
Stocking (the volume of a tree stand & overstocked & overstocked & well-stocked/ & well-stocked \\
$\begin{array}{l}\text { as compared with a desired level for } \\
\text { balanced health and growth) }\end{array}$ & & & & \\
\hline
\end{tabular}


study in 1979 entitled Bootstrap methods: Another look at jackknife [10]. In this study, a moving block bootstrap (MBB) method was applied, specific for dependent data [11] which, however, assumes that data is stationary (it means that the mean, variance and covariance do not change over time). The resulting border effect which appears during sampling was eliminated by the so-called circular block resampling. The solution proposed by Politis and Romano in 1992 makes observations without antecedents and consequences disappear [12].

A data stationarity check (moving block bootstrap method assumptions) was carried out by means of a Dickey-Fuller test described, among others, in a study entitled Econometrics Analysis [13]. An Augmented DF unit root test was used for practical calculations. The null hypothesis is accepted as a result of the implemented ADF test (implementation in free $\mathrm{R}-\mathrm{Cran}$ environment): $\mathrm{H}_{0}$ the process is nonstationary as opposed to $\mathrm{H}_{\mathrm{A}}$ which assumes that the process is stationary. The results of the stationary test (Table 3 ) are critical. The evaluated values are beyond the statistic range $\mathrm{DF}_{(0.05,1000)}=(-1.9294,-1.9576) ;$ and $\mathrm{H}_{0}$ should be rejected at a significance level $\alpha=0.05$, whereas the alternative
$\mathrm{H}_{\mathrm{A}}$ ought to be accepted, which points to the fact that the process is stationary. Implementing the MBB method made it possible to shorten calculations and the author was able to directly proceed to estimating test parameters using error-minimizing parameters recommended by Lahiri [11]. The number of bootstrap replications was assumed to be 1500 . The correctness of statistical estimation was based on the following parameters [11]:

$$
\begin{aligned}
& \text { mean squared error: } \\
& \left.\operatorname{MSE}\left(\theta_{-} \mathrm{n}^{\wedge} * \mid \theta\right)=\mathrm{E}\left(\theta_{-} \mathrm{n}^{\wedge}{ }^{*}-\theta\right)\right)^{\wedge} 2= \\
& \operatorname{Var}\left(\theta_{-} \mathrm{n}^{\wedge *}\right)+\left(\operatorname{BIAS}\left(\theta_{-} \mathrm{n}^{\wedge *} \mid \theta\right)\right)^{\wedge} 2 \\
& \text { bias of an estimator: } \\
& \operatorname{BIAS}\left(\theta_{-} \mathrm{n}^{\wedge} * \mid \theta\right)=\mathrm{E}_{-}{ }^{*}\left(\theta_{-} \mathrm{n}^{\wedge} *\right)-\theta \\
& \text { percentile confidence interval bootstrap type: } \\
& \mathrm{P}_{-} \mathrm{F}^{\sim}\left(\mathrm{q}_{-}(\alpha / 2)^{\wedge}{ }^{*} \leq \theta_{-} \mathrm{n}^{\wedge}{ }^{*}-\theta\left(\left(\mathrm{F}_{-} \mathrm{n}\right)^{\sim}\right) \leq\right. \\
& \text { q_ } \left.(1-\alpha / 2)^{\wedge *}\right)=1-\alpha
\end{aligned}
$$

\begin{tabular}{|c|c|c|}
\hline Variable & $\begin{array}{l}\text { Carbon monoxide } \\
\text { concentration } \\
\left(\mathrm{mg} \times \mathrm{m}^{-3}\right)\end{array}$ & $\begin{array}{c}\text { 15-min short-term carbon } \\
\text { monoxide concentration } \\
\left(\mathrm{mg} \times \mathrm{m}^{-3}\right)\end{array}$ \\
\hline TO_ET & 613.77 & 8592.73 \\
\hline TO_LT & 998.00 & 1093.16 \\
\hline CSOVarA_ET & 1042.81 & 613.23 \\
\hline CSOVarA_LT & 1456.32 & 389.99 \\
\hline CSOVarB_ET & 719.96 & 228.53 \\
\hline CSOVarB_LT & 1130.31 & 1581.90 \\
\hline PO_ET & 3194.32 & 5612.73 \\
\hline PO_LT & 2628.21 & 2203.39 \\
\hline
\end{tabular}

where:

$\theta\left(\left(\mathrm{F}_{-} \mathrm{n}\right)^{\sim}\right)$ - unknown parameter of the bootstrap probability function,

$\theta_{-} \mathrm{n}^{\wedge}{ }^{*}$ - bootstrap sample realization $\mathrm{X}_{-} 1, \ldots, \mathrm{X}_{-} \mathrm{n}$,

$\mathrm{q}_{-} \alpha^{\wedge *}$ - order- $\alpha$ quantile of a distribution function $\theta_{-} \mathrm{n}^{\wedge *}$ $\theta\left(\left(\mathrm{F}_{-} \mathrm{n}\right)^{\sim}\right)$.

Table 2. The value of $\mathrm{Chi}^{2}$ statistics for sample normality tests

TO_ET - skidding tractor operator, early thinning; TO_LT - skidding tractor operator, late thinning; CSOVarA_ET - chainsaw operator using skidding tractor technology, early thinning; CSOVarA_LT - chainsaw operator using skidding tractor technology, late thinning; CSOVarB_ET - chainsaw operator using processor technology, early thinning; CSOVarB_LT - chainsaw operator using processor technology, late thinning; PO_ET - processor operator, early thinning; PO_LT - processor operator, late thinning. 
Table 3. The results of augmented Dickey-Fuller stationarity tests*

\begin{tabular}{|c|c|c|}
\hline Variable & $\begin{array}{c}\text { Carbon monoxide } \\
\text { concentration } \\
\left(\mathrm{mg} \times \mathrm{m}^{-3}\right)\end{array}$ & $\begin{array}{l}\text { 15-min short-term carbon } \\
\text { monoxide concentration } \\
\left(\mathrm{mg} \times \mathrm{m}^{-3}\right)\end{array}$ \\
\hline TO_ET & -10.7473 & -9.9214 \\
\hline TO_LT & -10.6392 & -10.7184 \\
\hline CSOVarA_ET & -9.8991 & -9.4300 \\
\hline CSOVarA_LT & -9.2947 & -10.0320 \\
\hline CSOVarB_ET & -10.6774 & -10.4377 \\
\hline CSOVarB_LT & -9.8757 & -10.6187 \\
\hline PO_ET & -9.2012 & -9.1094 \\
\hline PO_LT & -9.7045 & -10.0340 \\
\hline
\end{tabular}

* Large order $9, \mathrm{p}<0.01$, adopted hypothesis $\mathrm{H}_{\mathrm{A}}$ : stationary. Abbreviations as in Table 2.

\section{RESULTS AND DISCUSSION}

The exposure limits for harmful or hazardous substances in the air have been defined in employment protection regulations. It is assumed that those limits must not be exceeded at a work station unless an employee has been protected. Polish regulations [14] specify that the $\mathrm{CO}$ permissible exposure limit must not be higher than $23 \mathrm{mg} \times \mathrm{m}^{-3}$ in the case of the 8-h time-weighted average permissible exposure limit (TWAEL) and $117 \mathrm{mg} \times \mathrm{m}^{-3}$ in the case of the $15-\mathrm{min}$ short-term exposure limit (STEL). Exceeding the 15-min short-term exposure limit must not occur more frequently than twice per work shift or once every hour.

The analysis of statistical BIAS (Tables 4-7) allows to notice that the values are practically equal to zero (14th decimal place). The Mean Squared Error (MSE), that is the expected value of the squared difference between an estimator and the value estimated for the average concentration (Table 4), varied from 0.002 for a skidding tractor operator during late thinning (TO_LT) to 4.1 for a petrol chainsaw operator applying processor technology during late thinning interventions (COSVarB_LT). The obtained ex-

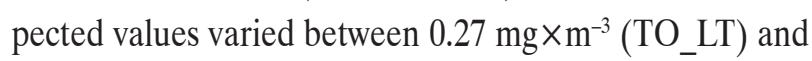
$34.55 \mathrm{mg} \times \mathrm{m}^{-3}$ (COSVarB_LT). The standard deviation

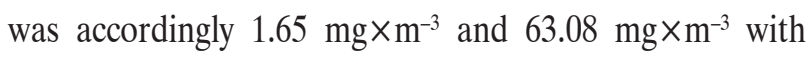
a mean square error of 0.0209 and 40.95 (Table 6).

Table 4 points to a low carbon monoxide concentration at the skidding tractor operator's working station $\left(0.27-2.54 \mathrm{mg} \times \mathrm{m}^{-3}\right)$. On the other hand, the CO level was higher than its normal concentration in the air $\left(0.125 \mathrm{mg} \times \mathrm{m}^{-3}\right)$ and did not exceed $6 \mathrm{mg} \times \mathrm{m}^{-3}$ typical for household rooms [15]. The highest $\mathrm{CO}$ concentration value $\left(10.35 \mathrm{mg} \times \mathrm{m}^{-3}\right)$ in a breathing area of a processor operator was observed during early thinning operations. Exceeding TWAEL was observed in three out of four analyzed work variants for a petrol chainsaw operator. The lowest mean concentration $\left(15.01 \mathrm{mg} \times \mathrm{m}^{-3}\right)$ was observed during late thinning individual operations (CSOVarA_LT). It should be noted that, while analyzing the mean 15-min short-term carbon monoxide concentration (Table 5), the highest maximum value $\left(100.26 \mathrm{mg} \times \mathrm{m}^{-3}\right)$ was observed at the work station of a chainsaw operator working individually (variant A) during early thinning interventions. This value is lower than STEL $\left(117 \mathrm{mg} \times \mathrm{m}^{-3}\right)$, therefore, it can be assumed that STEL of the other considered parameter, was not exceeded at any of the analyzed stations. Subject matter literature, however, does mention some instances of exceeding the STEL value [7]. 
Table 4. The mean and percentile confidence interval for the time-weighted average of the carbon monoxide concentration

\begin{tabular}{lccccccrc}
\hline Variable & TO_ET & TO_LT & CSOVarA_ET & CSOVarA_LT & CSOVarB_ET & CSOVarB_LT & PO_ET & PO_LT \\
\hline $\mathrm{E}_{*}\left(\theta^{*}\right)$ & 2.54 & 0.27 & 31.98 & 15.01 & 30.67 & 34.55 & 10.350 & 2.53 \\
$\mathrm{q}_{0.025}^{*}$ & 2.27 & 0.18 & 29.16 & 12.16 & 28.13 & 30.77 & 9.110 & 2.01 \\
$\mathrm{q}_{0.975}^{*}$ & 2.83 & 0.37 & 34.74 & 18.27 & 33.57 & 38.51 & 11.521 & 3.05 \\
Max & 123.00 & 34.00 & 526.00 & 460.00 & 676.00 & 734.00 & 112.000 & 36.00 \\
MSE & $2.14 \times 10^{-2}$ & $0.25 \times 10^{-2}$ & 2.18 & 2.29 & 1.88 & 4.10 & $0.39 \times 10^{-2}$ & $7.38 \times 10^{-2}$ \\
BIAS & $-5.63 \times 10^{-16}$ & $1.20 \times 10^{-16}$ & $2.14 \times 10^{-14}$ & $-1.82 \times 10^{-14}$ & $1.63 \times 10^{-14}$ & $2.27 \times 10^{-14}$ & $-1.45 \times 10^{-14}$ & $9.95 \times 10^{-16}$ \\
\hline
\end{tabular}

$\mathrm{E}_{*}\left(\theta^{*}\right)$ - average value bootstrap type; $\mathrm{q}_{\alpha}^{*}$ - order- $\alpha$ quantile; Max - maximum value; MSE - mean squared error; BIAS - a tendency of an estimate to deviate from a true value.

Other abbreviations as in Table 2.

Table 5. The mean and percentile confidence interval for the 15-min short-term carbon monoxide concentration

\begin{tabular}{lcccccccc}
\hline Variable & TO_ET & TO_LT & CSOVarA_ET & CSOVarA_LT & CSOVarB_ET & CSOVarB_LT & PO_ET & PO_LT \\
\hline $\mathrm{E}_{*}\left(\theta^{*}\right)$ & 2.40 & 0.720 & 31.90 & 14.23 & 34.38 & 36.04 & 10.23 & 2.58 \\
$\mathrm{q}_{0.025}^{*}$ & 2.20 & 0.510 & 30.07 & 13.25 & 32.98 & 34.56 & 8.96 & 2.07 \\
$\mathrm{q}_{0.975}^{*}$ & 2.63 & 0.980 & 33.63 & 15.26 & 35.75 & 37.38 & 11.51 & 3.09 \\
Max & 7.95 & 34.543 & 100.26 & 74.83 & 93.30 & 96.95 & 70.19 & 35.61 \\
MSE & $1.18 \times 10^{-2}$ & $1.33 \times 10^{-2}$ & $0.81 \times 10^{-2}$ & $25.58 \times 10^{-2}$ & $51.50 \times 10^{-2}$ & $53.05 \times 10^{-2}$ & $44.33 \times 10^{-2}$ & $7.08 \times 10^{-2}$ \\
BIAS & $-1.24 \times 10^{-15}$ & $-1.79 \times 10^{-16}$ & $4.25 \times 10^{-14}$ & $3.77 \times 10^{-15}$ & $9.40 \times 10^{-16}$ & $6.27 \times 10^{-14}$ & $1.09 \times 10^{-14}$ & $1.99 \times 10^{-15}$ \\
\hline
\end{tabular}

Abbreviations as in Tables 2 and 4.

Table 6. The standard deviation and percentile confidence interval for the time-weighted carbon monoxide concentration

\begin{tabular}{lcccccccc}
\hline Variable & TO_ET & TO_LT & CSOVarA_ET & CSOVarA_LT & CSOVarB_ET & CSOVarB_LT & PO_ET & PO_LT \\
\hline SD $_{*}\left(\theta^{*}\right)$ & 5.0200 & 1.6500 & 52.5350 & 43.4800 & 46.7000 & 63.0800 & 20.2800 & 7.7700 \\
$\mathrm{q}^{*}$ & 3.3500 & 0.7700 & 46.4550 & 31.9000 & 36.9200 & 51.3700 & 18.9700 & 6.9400 \\
$\mathrm{q}^{*}{ }_{0.975}$ & 7.5500 & 2.5000 & 59.4200 & 55.0200 & 57.4800 & 75.7100 & 21.4400 & 8.5700 \\
MSE & 1.8811 & 0.2085 & 11.1119 & 33.8807 & 28.0942 & 40.9447 & 0.4047 & 0.1843 \\
BIAS & $-8.25 \times 10^{-15}$ & $-1.26 \times 10^{-15}$ & $4.58 \times 10^{-14}$ & $-4.50 \times 10^{-17}$ & $2.12 \times 10^{-14}$ & $-2.19 \times 10^{-14}$ & $-6.77 \times 10^{-15}$ & $2.10 \times 10^{-15}$ \\
\hline
\end{tabular}

SD - standard deviation.

Other abbreviations as in Tables 2 and 4.

It was assumed further during the analysis process that the estimated parameters of statistical distributions are normally distributed in accordance with the central limit theorem [11]. The resulting bootstrap average values and standard deviation values make it possible to verify the hypotheses regarding the influence of each technology variant on the carbon monoxide concentration in a breathing area.

Since the permissible limit $\left(23 \mathrm{mg} \times \mathrm{m}^{-3}\right)$ was exceeded merely in the breathing area of a chainsaw operator, the hypotheses analysis was limited to this particular work station only. The results of the Student's t-test (Table 8) 
Table 7. The standard deviation and percentile confidence interval for the 15-min short-term carbon monoxide concentration

\begin{tabular}{lcccccccc}
\hline Variable & TO_ET & TO_LT & CSOVarA_ET & CSOVarA_LT & CSOVarB_ET & CSOVarB_LT & PO_ET & PO_LT \\
\hline SD $_{*}\left(\theta^{*}\right)$ & 3.3500 & 3.6600 & 26.3900 & 15.7500 & 21.1700 & 22.4100 & 19.9600 & 7.7600 \\
$\mathrm{q}_{0.025}^{*}$ & 3.2600 & 2.6200 & 25.3700 & 14.5700 & 20.3700 & 21.3800 & 18.7100 & 6.9000 \\
$\mathrm{q}_{0.975}^{*}$ & 3.4400 & 4.6500 & 27.3900 & 16.8800 & 22.0500 & 23.4500 & 21.1700 & 8.5600 \\
MSE & 0.0019 & 0.2577 & 0.2739 & 0.3680 & 0.1976 & 0.2801 & 0.4094 & 0.1874 \\
BIAS & $1.19 \times 10^{-15}$ & $1.75 \times 10^{-17}$ & $4.94 \times 10^{-14}$ & $1.99 \times 10^{-15}$ & $-1.48 \times 10^{-14}$ & $-4.03 \times 10^{-16}$ & $1.61 \times 10^{-14}$ & $7.57 \times 10^{-15}$ \\
\hline
\end{tabular}

Abbreviations as in Tables 2, 4 and 6.

Table 8. The probability value of the Student's t-statistic, $p$

\begin{tabular}{llcc}
\hline Variable 1 & Variable 2 & Time-weighted average & $\begin{array}{c}\text { 15-min short-term } \\
\text { weighted average }\end{array}$ \\
\hline CSOVarA_ET & CSOVarA_LT & 0.0000 & 0.0000 \\
& CSOVarB_ET & 0.4705 & 0.0046 \\
& CSOVarB_LT & 0.2254 & 0.0000 \\
CSOVarA_LT & CSOVarB_ET & 0.0000 & 0.0000 \\
& CSOVarB_LT & 0.0000 & 0.0000 \\
CSOVarB_ET & CSOVarB_LT & 0.0556 & 0.0371 \\
\hline
\end{tabular}

Abbreviations as in Table 2.

of the mean time-weighted average show that a statistically significant difference at the level of $\alpha=0.05$ was observed in the case of variant A late thinning chainsaw operator. In the remaining analyzed cases, null hypothesis on the equality of mean values should not be rejected.

Comparing cases 2, 3 and 6 (Table 8, column 3), one may formulate a general conclusion that 2 considered variants of a chainsaw operator's work (A - individual work, B - coworking with a processor's operator) did not influence the average daily $\mathrm{CO}$ concentration. This influence turned out to be important in the case of testing hypotheses on the equality of 15 -min short-term weighted average (Table 8, column 4).

Author's research into forest workers' load [16] points to lower physical work intensity (by even as much as 30\%) in the case of individual work. It caused a decrease of average work productivity in effective time, from $9.78 \mathrm{~m}^{3} \times \mathrm{h}^{-1}$ (variant B) to $1.89 \mathrm{~m}^{3} \times \mathrm{h}^{-1}$ (variant A) [17]. This allows to assume that there are time pressure elements present in variant $B$ and that lower $C O$ concentration in variant $A$ of chainsaw operator's work during late thinning interventions (CSOVarA_LT) was the effect of the change in a working day structure. Variant A of chainsaw operator's work fostered more frequent rest breaks and engineering time [16], which significantly lowered CO concentration numbers.

Research into the potential outcomes of petrol chainsaw operators' exposure to $\mathrm{CO}$ carried out in the British Columbia [18] showed high inter-individual variations. The authors who have been quoted here expressed an opinion that the source of observed differences in hemoglobin saturation with $\mathrm{CO}$ was related to both work intensity and the level of physical fitness, as these factors determine frequency of breath, which is a major path for $\mathrm{CO}$ intake into a human organism. 
The level of carboxyhemoglobin observed in petrol chainsaw operators [19] exceeded the allowable biological exposure index (BEI) recommended by the American Conference of Governmental Industrial Hygienists by 3.5\%. Daily CO concentration analyses in the breathing area of forest workers [7] show that exceeding TWAEL is not permanent and its probability equals to $25 \%$.

Research carried out by other authors while logging in heavy timber stands points to exceeding STEL even by a few times and up to the level of $500 \mathrm{mg} \times \mathrm{m}^{-3}[2,19]$. A CO concentration increase in a breathing area can be fostered by, among other things, unfavorable weather or terrain conditions and the manner of operating a petrol chainsaw. Additionally, the piecework system is considered to increase the $\mathrm{CO}$ concentration in a breathing zone as the maximum carboxyhemoglobin level can be observed within just 2-3 h after the exposure [19].

Although exceeding the permissible hygienic levels is not permanent, the observed $\mathrm{CO}$ concentration may cause splitting headaches and cardiovascular system disorders, which cause that workers make more mistakes and behave worse in the working environment.

\section{CONCLUSIONS}

The analysis of the carbon monoxide concentration in breathing areas of forest workers using motor-manual work technologies shows significant right-skewness. A nonparametric method was used in order to specify the characteristics of the collected sets. Having checked the results of the moving block bootstrap method which had been applied in the study, it was discovered that both the values of an average $\mathrm{CO}$ concentration and the values of variance and covariance do not change over time. Bootstrap average values show that the average $\mathrm{CO}$ concentration at a skidding tractor operator's station during early thinning was $2.54 \mathrm{mg} \times \mathrm{m}^{-3}$. At a processor operator's station it amounted to $10.35 \mathrm{mg} \times \mathrm{m}^{-3}$. Such results allow to conclude that a higher $\mathrm{CO}$ concentration at the 2 above-mentioned work stations was observed during early thinning. The recorded concentration, however, does not exceed any of the 2 maximum permissible concentration limits.

In the case of a petrol chainsaw operator, it was observed that the permissible exposure limit $\left(23 \mathrm{mg} \times \mathrm{m}^{-3}\right)$ was exceeded and the short-term permissible exposure limit was not. The average concentration value for a chainsaw operator working individually during late thinning interventions (CSOVarA_LT) was substantially lower $\left(15.01 \mathrm{mg} \times \mathrm{m}^{-3}\right)$, which results from lack of technological pressure that can be observed while cooperating with a processor operator. The result of a Student's t-test, however, allows the author of this study to formulate a general conclusion that the 2 variants of chainsaw operator's work ( $\mathrm{A}$ - individual work, $\mathrm{B}$ - co-working with a processor operator) did not influence the average daily $\mathrm{CO}$ concentration. This influence turned out to be statistically significant for the short-term (15-min) concentration, the value of which was much lower than the standard values in each of the analyzed cases.

A review of the subject matter literature allows to note that there is even a $25 \%$ probability of exceeding the maximum permissible $\mathrm{CO}$ concentration level for a chainsaw operator. The observed concentration may cause splitting headaches and cardiovascular system disorders. The risk increases along with conditions that contribute to the concentration of exhaust produced by 2 -stroke petrol chainsaw engines.

\section{REFERENCES}

1. Ruth-Sahd LA, Zulkosky K, Fetter ME. Carbon monoxide poisoning: Case studies and review. Dimens Crit Care Nurs. 2011;30:303-14, http://dx.doi.org/10.1097/DCC. 0b013e31822fb017.

2. Slaughter JC, Koenig JQ, Reinhardt TE. Association between lung function and exposure to smoke among firefighters at prescribed burns. J Occup Environ Hyg. 2004;1(1): 45-9, http://dx.doi.org/10.1080/15459620490264490. 
3. McMahon CK. Forest fires and smoke - Impacts on air quality and human health in the USA. Proceedings of TAPPI International Environmental Conference; 1999 Apr 18-21; Nashville (TN), USA. Atlanta: TAPPI Press; 1999;1-3, p. 443-53.

4. Athanassiadis D. Energy consumption and exhaust emissions in mechanized timber harvesting operations in Sweden. Sci Total Environ. 2000;255(1-3):135-43, http://dx.doi. org/10.1016/S0048-9697(00)00463-0.

5. Lijewski P, Merkisz JFP. Research of exhaust emissions from a harvester diesel engine with the use of portable emission measurement system. Croat J Forest Eng. 2013 [cited 2013 Oct 15];34(1):113-23. Available from: http://www.crojfe. com/r/i/lijewski_113-122.pdf.

6. Magagnotti N, Picchi G, Sciarra G, Spinelli R. Exposure of mobile chipper operators to diesel exhaust. Ann Occup Hyg. 2014;58(2):217-26, http://dx.doi.org/10.1093/annhyg/ met059.

7. Sowa J, Leszczyński K. Emission of carbon monoxide during work with a power chain saw and cable winch propelled by a chain saw engine. In: Sowa J, Barszcz J, Sosnowski A, editors. International Scientific Conference "Ecological, Ergonomic and Economical Optimization of Forest Utilization in Sustainable Forest Management"; 2005 June 15-18; Kraków-Krynica, Poland. Kraków: Publishing House of the University of Agriculture in Krakow; 2005. p. 375-93.

8. Fisz M. Probability theory and mathematical statistics. 3rd ed. New York, London, Sydney: John Wiley \& Sons, Inc; 1967.

9. Dudek A, Goćwin M, Leśkow J. Simultaneous confidence bands for the integrated hazard function. Comput Stat. 2007; 23(1):41-62, http://dx.doi.org/10.1007/s00180-007-0067-7.

10. Mammen E, Nandi S. Bootstrap and resampling. In: Mori WHY, Gentle JE, editors. Handbook of computational statistics. Berlin-London: Springer; 2004. p. 467-96.
11. Lahiri SN. Resampling methods for dependent data. 1st ed. Berlin: Springer; 2003 [cited 2013 October 15]. p. 4-5. Available from: http://dx.doi.org/10.1007/978-1-4757-3803-2.

12. Dudek A, Leśkow J. A bootstrap algorithm for data from a periodic multiplicative intensity function. Commun Stat Theor Meth. 2011;40(8):1468-89, http://dx.doi.org/10.1080/ 03610921003615849.

13. Greene WH. Econometric analysis. 5th ed. New Jersey: Prentice Hall; 2003.

14. [The regulation on maximum concentrations and intensities of factors harmful to health in the work environment. J Laws 2005 No. 212, item 1769 (October 10, 2005)]. Polish.

15. Green W. An introduction to indoor air quality: Carbon monoxide (CO). United States Environmental Protection Agency; 2008 [cited 2013 Oct 15]. p. 6. Available from: http:// www.epa.gov/iaq/co.html.

16. Leszczyński K. [The evaluation of selected aspects of timber harvesting technologies. Research methodology]. 1st ed. Kraków: Publishing House of the University of Agriculture in Krakow; 2011. Polish.

17. Stańczykiewicz A, Leszczyński K. [The report from the research project No. NN309423533: Research on the optimization of eco-technology in thinning coniferous stands by application of tractor processor]. Kraków: University of Agriculture in Krakow. Forthcoming 2011. Polish.

18. van Netten C, Brubaker RL, Mackenzie CJ, Godolphin WJ. Blood lead and carboxyhemoglobin levels in chainsaw operators. Environ Res. 1987;43:244-50, http://dx.doi.org/10.1016/ S0013-9351(87)80075-0.

19. Bünger J, Bombosch F, Mesecke U, Hallier E. Monitoring and analysis of occupational exposure to chain saw exhausts. Am Ind Hyg Assoc J. 1997;58(10):747-51, http://dx.doi. org/10.1080/15428119791012405.

This work is available in Open Access model and licensed under a Creative Commons Attribution-NonCommercial 3.0 Poland License - http://creativecommons.org/ licenses/by-nc/3.0/pl/deed.en. 